\title{
Entomopathogenic fungus, Metarhizium anisopliae, anchored onto MCM-41 silica nanomaterial: A novel and effective insecticide against potato tuber moth in stored potatoes
}

\author{
F. Khorrami ${ }^{1 *}$, A. Soleymanzade ${ }^{2}$, H. Batmani ${ }^{3}$ and Y. Ghosta ${ }^{4}$
}

Summary Phthorimaea operculella (PTM) is an economically significant invasive potato insect pest in tropical and sub-tropical regions. Due to many problems concerning chemical insecticides, biocontrol agents such as entomopathogenic fungi have attracted researchers' interest regarding their application as a part of integrated potato tuber moth management strategies in several countries. Hence, in the present study, we examined the lethal effects of entomopathogenic fungus, Metarhizium anisopliae (used as pure culture (PEF) or formulated with MCM-41 silica nanomaterial (MCM-41@fungus)) on eggs and neonate larvae of PTM. The MCM-41was completely characterized by Fourier transform infrared (FT-IR), Scanning Electron Microscopy (SEM), Energy Dispersive X-ray (EDS), X-ray diffraction (XRD), and Thermogravimetric analysis (TGA) techniques. The morphology of MCM-41@fungus was evaluated by scanning electron microscope (SEM). The morphology of the mesoporous structure was exhibited to be homogeneous, regular, and spherical. $L C_{50}$ values of PEF and MCM-41@fungus were estimated to be $1.7 \times 10^{7}$ and $2 \times 10^{5}$ conidia/ml for eggs and $1.8 \times 10^{6}$ and $1.5 \times 10^{4}$ conidia/ml for neonate larvae, respectively. Hence, bioassays demonstrated that MCM-41@fungus was more toxic than the pure culture at egg and neonate larval stages of the pest. The results exhibited that pure $M$. anisopliae and its nanoformulation could play key roles as biopesticides in management programmes of $P$. operculella.

Additional keywords: bio-pesticide, MCM-41, Metarhizium anisopliae, nano-formulation, Phthorimaea operculella, toxicity

\section{Introduction}

Potato (Solanum tuberosum L. (Solanaceae)) is one of the most important agricultural products that plays a major role as a high value crop for human health and food industry. Among foods, it has the fourth rank in the world after wheat, rice, and corn (Germchi et al., 2011). Potato tuber moth (PTM), Phthorimaea operculella Zeller (Lepidoptera: Gelechiidae) is considered as the most damaging potato insect pest in the world (Radcliffe, 1982). PTM occurs in tropical and subtropical regions where potato is cultivated

\footnotetext{
Department of Plant Protection, Faculty of Agriculture, Urmia University, Urmia, Iran.

2 Department of Plant Protection, Faculty of Agriculture, Urmia University, Urmia, Iran.

${ }^{3}$ Yong Researchers and Elite Club, Sanandaj Branch, Islamic Azad University, Sanandaj, Iran.

${ }^{4}$ Department of Plant Protection, Faculty of Agriculture, Urmia University, Urmia, Iran

* Corresponding author: fkh.khorrami@gmail.com
}

and it causes notable crop yield losses (Kroschel and Sporleder, 2006). Since potato plants resist some PTM damages, protection of stored potatoes against larvae of the pest is more important than in the field (Lacey, 2012). When tubers infested by PTM enter storage without chemical treatment, the larvae continue to develop, make tunnels and pollute the tubers with their frasses and finally the decaying organisms can enter the plant (Radcliffe, 1982).

Extensive use of chemical insecticides has resulted in adverse effects on environment and human health. Particularly, excessive application of non-selective chemical insecticides can destroy natural enemies of the pest and beneficial organisms and induce problems such as development of pest resistance (Sharma and Gupta, 2009). These adverse effects urged the development of alternative pest management tactics in which microbial controls may play principal 
roles (Collantes et al., 1986; Llanderal-Cázares et al., 1996).

Entomopathogenic fungi are efficient microbial control agents of several pests (Goettel et al., 2005), including some key insect pests of potato (Lacey et al., 1999; Wraight and Ramos, 2005). The entomopathogenic filamentous fungus Metarhizium anisopliae is a common pathogen of arthropods applied in biological control strategies against numerous serious insect pests (Santi et al., 2010). In spite of the potential of entomopathogenic fungi in pest control, these biocontrol agents have some disadvantages including sensitivity to environmental factors such as moisture, light, and temperature that have limited their applications under storage and field conditions. However, these problems can be overcome through recent technological advances such as nano-formulation approaches which can improve their efficacy and pathogenicity and will permit future use of entomopathogenic fungi in crop production systems. In this respect, the hexagonal array of uniform mesoporous MCM-41 with particular properties such as exceptionally high surface areas and high pore volumes (Chen et al., 1993; Rath and Parida, 2011) attracted our interest in applying it in plant protection and insect pest management. Since it has 1-D uniform mesopores, the entomopathogenic fungi can be grafted into MCM41. Consequently, we selected MCM-41 as a support which belongs to M41S family and is mainly made up of silica, $\mathrm{SiO}_{2}$, as a carrying agent (Shylesh and Singh, 2005; Rath and Parida, 2011). Silica has unique benefits such as extraordinary thermal and chemical stability, ease of handling, and abundance of exposed silanol (Si-OH) groups (Abdollahi-Alibeik and Pouriayevali, 2011).

\section{Materials and Methods}

Phthorimaea operculella rearing, $M$. anisopliae culture, nano-formulation

\section{Insect rearing}

A colony of potato tuber moth was ob- tained from the University of Mohaghegh Ardabili, Ardabil, Iran. The colony was continuously reared on Agria potato cultivar. Experiments were carried out under laboratory conditions at $26 \pm 1{ }^{\circ} \mathrm{C}, 60 \pm 5 \% \mathrm{RH}$ and photoperiod of 8:16 (L:D). To achieve cohort eggs of $P$. operculella, 30 male-female pairs of newly emerged moths were kept inside cylindrical containers. The adults were fed using a piece of cotton imbued with a $10 \%$ honey-water solution. Cylindrical containers were covered with a fine mesh netting on the heads. Filter papers were placed on the head of containers which provided an oviposition site for moths (Golizadeh and Zalucki, 2012).

\section{Microorganism and culture media}

The entomopathogenic fungus, $M$. anisopliae (DS12) was provided from Mycology Collections of Urmia University, Urmia, Iran. This isolate was originally obtained from wheat samples collected from Urmia, Iran. Stock cultures of the isolate were grown on potato dextrose agar slants (PDA; Merck, Germany) and stored at $4^{\circ} \mathrm{C}$ for future uses. Subcultures were prepared by transferring pieces of stock cultures onto new PDA plates and incubated at $25 \pm 1^{\circ} \mathrm{C}$ for 14 days before use in experiments. Conidia were harvested by flooding the cultures with sterile distilled water containing $0.02 \%$ Tween- 80 and scraping with a sterile L-shaped glass rod. Concentrations of the resulting stock suspension were determined using a Neubauer hemocytom-

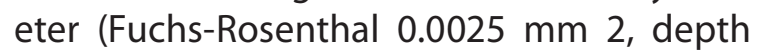
$0.100 \mathrm{~mm}, \mathrm{VWR}$, Sweden). Germination was surveyed under a light microscope (400X). A conidium was considered germinated when the germ tube was expanded beyond its width (Inglis et al., 2012). The mean germination rate for M. anisopliae was $96 \%$.

Preparation of siliceous MCM-41

Mesoporous Si-MCM-41 was synthesized through Sol-gel method according to

Cai et al. (2001).

Preparation of siliceous MCM-41-(CH2)3Cl The resulted MCM-41 powder (4.8g) with 5.0g 3-chloropropyltrimethoxysilane (CPT- 
MS) was added to $\mathrm{n}$-hexane $(96 \mathrm{ml})$ and the mixture was stirred under refluxing and nitrogen atmosphere for $24 \mathrm{~h}$. The obtained sediments were collected by filtration, were washed with n-hexane for several times, and eventually dried under vacuum to obtain MCM-41-(CH2)3-Cl.

Preparation of MCM-41-entomopathogenic fungus

In a $100 \mathrm{ml}$ round bottom flask, a mixture of $\mathrm{MCM}-41-\mathrm{Cl}(1 \mathrm{~g})$, entomopathogenic fungus ( $10 \mathrm{ml}$ of determined concentrations) and $\mathrm{Et}_{3} \mathrm{~N}(1.5 \mathrm{ml})$ in $\mathrm{H}_{2} \mathrm{O}(50 \mathrm{ml})$ were stirred under room temperature for $24 \mathrm{~h}$. Then, the final product was dried at room temperature.

\section{Particle morphology studies}

Particle morphology was surveyed by a scanning electron microscope (SEM) (Day Petronic Company, Tehran, Iran), using FESEMTESCAN MIRA3. Thermogravimetric analysis (TGA) curves were recorded on a Shimadzu DTG-60 instrument (University of Kurdistan,
Sanandaj, Iran). Fourier transform infrared (FT-IR) spectra were recorded with $\mathrm{KBr}$ pellets on a Nexus 670 FT-IR spectrometer (Medical Sciences of Urmia University, Urmia, Iran). X-ray power diffraction (XRD) patterns were collected on Scintag PAD V X-ray diffractometer using a Co radiation source with wavelength $\lambda=1.78897 \AA, 40$ kV (Shahid Beheshti University, Tehran, Iran). The samples were scanned in the range of $2 \theta=1-10^{\circ}$.

M. anisopliae was grafted into MCM-41 which led to the synthesis of MCM-41@fungus. The details of MCM-41@fungus preparation procedure are presented in Scheme 1.

\section{Bioassays}

\section{Effect on larvae}

To examine larval mortality, each potato was dipped in suspensions of pure entomopathogenic fungus and MCM-41@fungus, separately, which were determined by preliminary dose setting experiments. Concentrations of PEF and MCM-41@fungus were
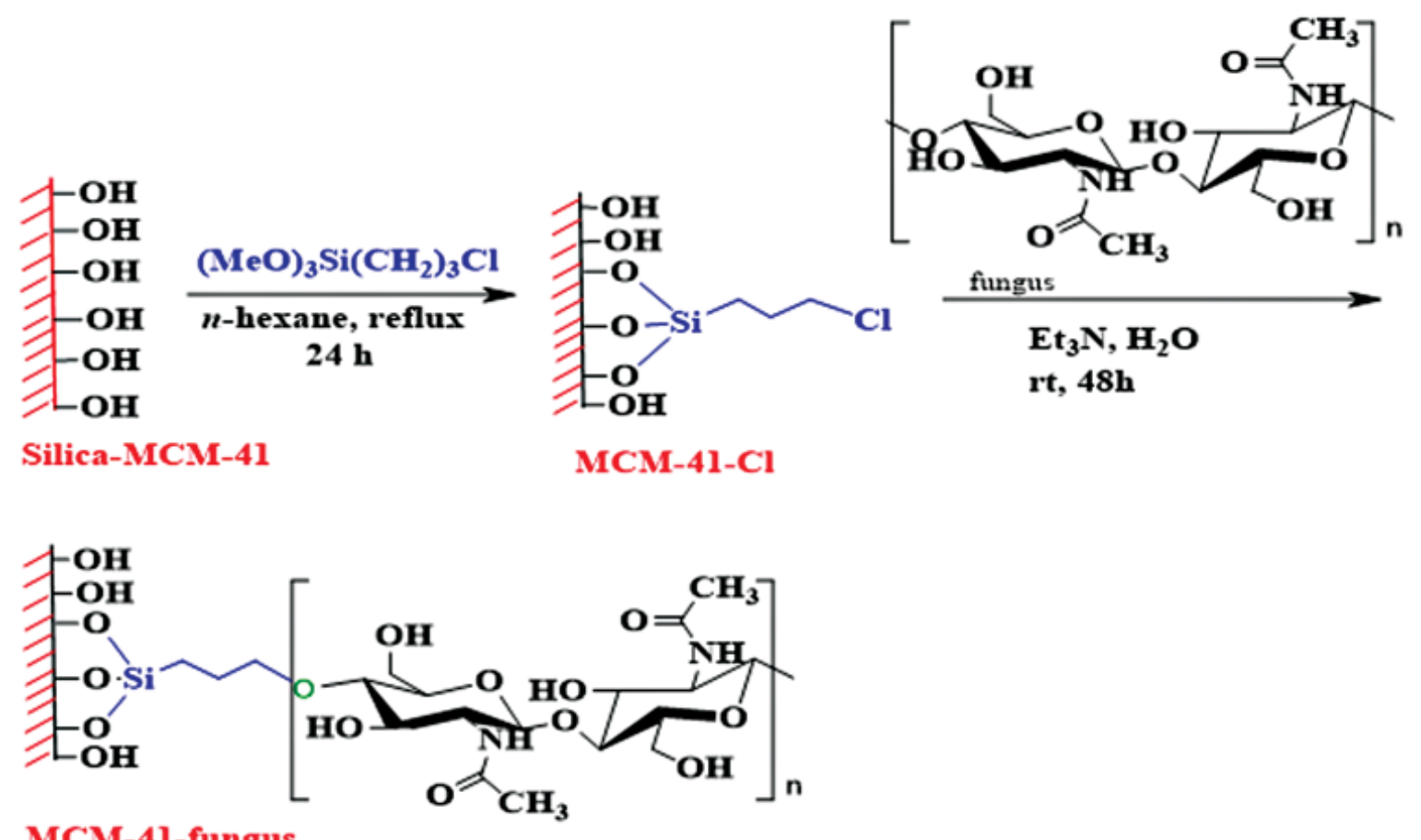

$\mathrm{n}=$ fungus structure

Scheme 1. Synthesis of MCM-41@fungus. CPTMS was anchored onto MCM-41 and Metarhizium anisopliae was grafted to CPTMS via its hydroxyl groups. 
in the ranges of $10^{4}-10^{8}$ and $10^{2}-10^{6}$ conidia/ ml, respectively. In MCM-41@fungus treatments, $0.1 \mathrm{~g}$ of each nano-composite was dispersed in $100 \mathrm{ml}$ distilled water containing $0.02 \%$ Tween-80 until water absorbance was stabilized. After shaking and product dispersion, potato tubers were dipped in the corresponding solutions for $15 \mathrm{~s}$. When water was evaporated and tubers were dried, potato tubers were transferred into plastic containers with ventilated lids that were kept at $26 \pm 1{ }^{\circ} \mathrm{C}, 60 \pm 5 \% \mathrm{RH}$ and a photoperiod of $8 \mathrm{~L}: 16 \mathrm{D}$. Then, 20 newly emerged larvae $(<5 \mathrm{~h}$ old) were placed on each tuber using a soft hair brush. Criterion of larval penetration was the number of adult emergence in all experiments. Each treatment and dose level (5 concentrations) was replicated three times.

\section{Effect on egg hatching}

PEF and MCM-41@fungus were tested at $10^{5}-10^{9}$ and $10^{3}-10^{7}$ conidia/ml, respectively. For treatments, filter papers containing 20 one-day-old eggs/each concentration were separately dipped in solutions of PEF and MCM-41@fungus. Preparation of MCM-41@ fungus treatments was carried out in a similar way to the previous one. When filter papers dried, they were transferred into plastic containers with ventilated lids containing intact potato tubers to stimulate egg hatching. The containers were kept under laboratory conditions $\left(26 \pm 1{ }^{\circ} \mathrm{C}, 60 \pm 5 \% \mathrm{RH}\right.$ and a photoperiod of $8 \mathrm{~L}: 16 \mathrm{D})$. Egg hatch was investigated using a light microscope after eight days. Each treatment was replicated three times.

\section{Statistical analysis}

In order to determine $\mathrm{LC}_{50}$ values, the data were analyzed utilizing probit procedures with software SPSS for Windows ${ }^{\circledR}$ version16.

\section{Results and Discussion}

Characterization of MCM-41 substrate and its use as a carrying agent in nano-

\section{formulation of $M$. anisopliae}

Fungus was supported on mesoporous MCM-41 which was completely characterized by Fourier transform infrared (FTIR), Scanning Electron Microscopy (SEM), Energy Dispersive X-ray (EDS), X-ray diffraction (XRD), and Thermogravimetric analysis (TGA) techniques.

Fourier transform infrared (FT-IR) spectra, recorded separately at different steps of MCM-41@fungus synthesis, can be observed in curves $a-b$ of Figure 1. As presented in curve $a$, for MCM-41 sample, the absorption bands at 1230, 1058.07, 812.10, and $463.30 \mathrm{~cm}^{-1}$ were assigned to asymmetric and symmetric stretching vibrations of mesoporous framework (Si-O-Si). The band at $3431.91 \mathrm{~cm}^{-1}$ was attributed to the stretching vibration of $\mathrm{O}-\mathrm{H}$ groups. Curve $\mathrm{b}$ demonstrated stretching vibrations at 1520.45 (C-N), and $1690.89 \mathrm{~cm}^{-1}(\mathrm{C}=\mathrm{O})$ and a broad band at around $3440.07 \mathrm{~cm}^{-1}(\mathrm{O}-\mathrm{H}$ and $\mathrm{N}-\mathrm{H})$. The band at $1375.95 \mathrm{~cm}^{-1}$ corresponded to the bending vibration of $\mathrm{CH}_{3}$ group, and the presence of the anchored CPTMS group was confirmed by $\mathrm{C}-\mathrm{H}$ stretching vibrations at 2950 and $2865 \mathrm{~cm}^{-1}$ for MCM-41@fungus.

The Energy Dispersive X-ray (EDS) of mesoporous MCM-41@fungus displays the grafting of fungus onto MCM-41 surface (Fig. 1). The results showed that there were only $\mathrm{C}, \mathrm{Si}, \mathrm{O}$, and $\mathrm{N}$ elements in the nano-pores with relative mass percentages of 15.50 , 48.81, 32.15, and 3.54\%, respectively (Fig. 2). Scanning electron microscope (SEM) micrograph of mesoporous MCM-41@fungus is demonstrated in Figure 3, showing that the particles were in nano range $(<100 \mathrm{~nm})$. The morphology of the mesoporous MCM41@fungus was homogeneous, regular, and spherical. Figure 4 demonstrates slow angle X-ray powder diffraction pattern of the samples (MCM-41 and MCM-41@fungus). XRD pattern of MCM-41 displayed three reflection peaks corresponding to d100 plane (very strong reflection) at $2 \theta=2.37^{\circ}$ and two peaks at d110 and d200 planes (weaker reflections) at $2 \theta=4.3^{\circ}$ and $4.48^{\circ}$, respectively, which can be attributed to the hexagonal structure of MCM-41. The values of spacing 


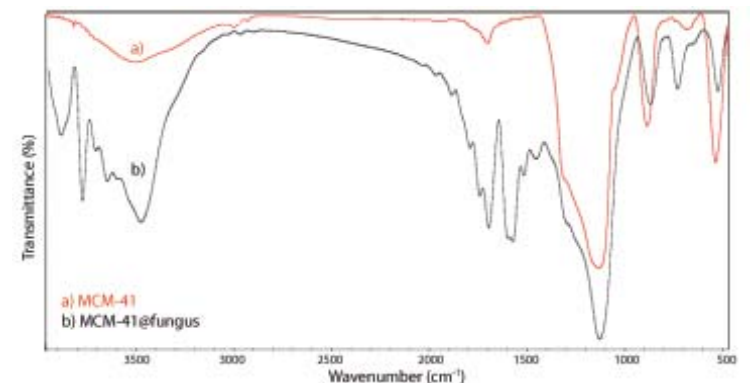

Figure 1. (a) Fourier transform infrared (FT-IR) spectra of MCM-41 and (b) MCM-41@fungus of the entomopathogenic fungus Metarhizium anisopliae.

In curve a, for MCM-41 sample, the absorption bands at 1230 , $1058.07,812.10$, and $463.30 \mathrm{~cm}^{-1}$ were assigned to asymmetric and symmetric stretching vibrations of mesoporous framework (Si-0-Si). The band at $3431.91 \mathrm{~cm}^{-1}$ was attributed to the stretching vibration of $0-\mathrm{H}$ groups.

Curve b demonstrated stretching vibrations at 1520.45 (C-N), and $1690.89 \mathrm{~cm}^{-1}(\mathrm{C}=0)$ and a broad band at around 3440.07 $\mathrm{cm}^{-1}(0-\mathrm{H}$ and $\mathrm{N}-\mathrm{H})$. The band at $1375.95 \mathrm{~cm}^{-1}$ corresponded to the bending vibration of $\mathrm{CH}_{3}$ group, and the presence of the anchored CPTMS group was confirmed by $\mathrm{C}-\mathrm{H}$ stretching vibrations at 2950 and $2865 \mathrm{~cm}^{-1}$ for MCM-41@fungus.

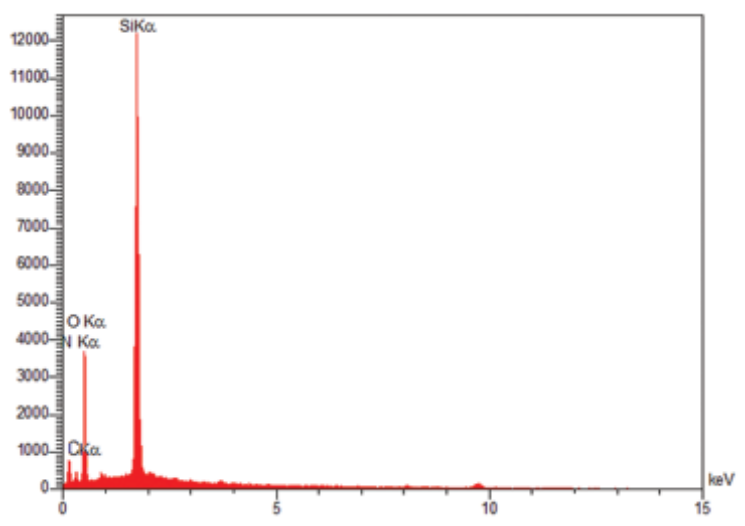

Figure 2. Energy Dispersive X-ray (EDS) spectrum of MCM41@fungus of the entomopathogenic fungus Metarhizium anisopliae: There were only $\mathrm{C}, \mathrm{Si}, \mathrm{O}$, and $\mathrm{N}$ elements in the nano pores with relative mass percentages of $15.50,48.81$, 32.15 , and $3.54 \%$, respectively.

(100) for XRD patterns of MCM-41 and MCM41@fungus were 37.14 and $32.98 \AA ⿱$, respectively. As demonstrated, after functionalization steps, a considerable decrease in XRD peak intensities was observed which caused variations in wall thickness and might be due to the reduction of scattering contrast between the channel wall of silicate framework and fungus. Therefore, it can be concluded that the grafting of fungus occurred

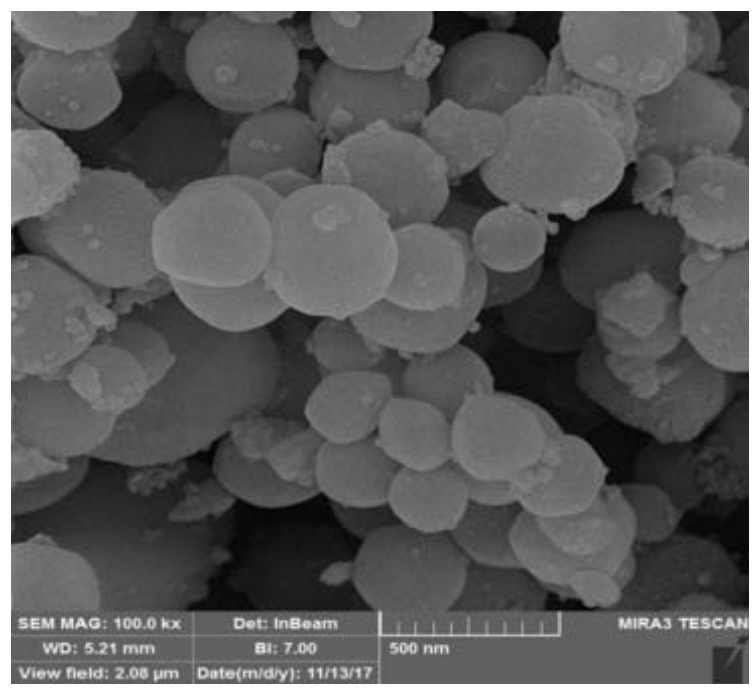

Figure 3. SEM image of MCM-41@fungus mesoporous of the entomopathogenic fungus Metarhizium anisopliae: The particles are observed to be in the nano range $(<100 \mathrm{~nm})$. The mesoporous presents homogeneous, regular, and spherical morphology.

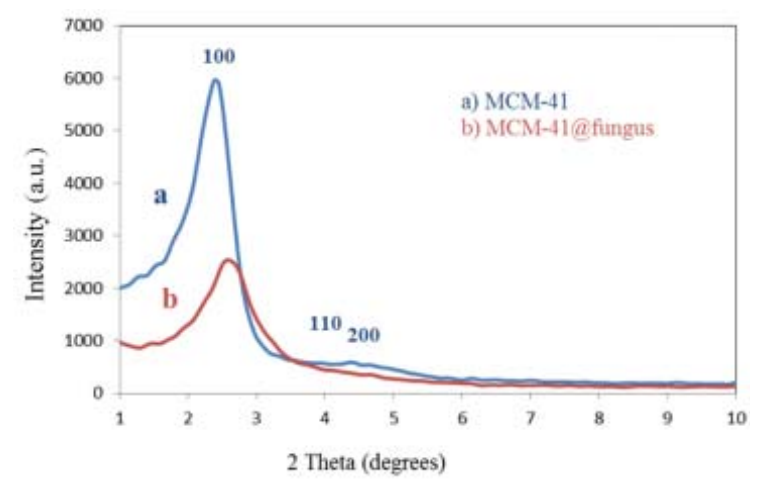

Figure 4. (a) X-ray diffraction (XRD) patterns of MCM-41 and (b) MCM-41@fungus of the entomopathogenic fungus Metarhizium anisopliae: The values of spacing (100) for XRD patterns of MCM-41 and MCM-41@fungus were 37.14 and 32.98 $\AA$, respectively. As demonstrated, after functionalization steps, a considerable decrease in XRD peak intensities was also observed.

in the inner pore channels of Si-MCM-41.

Thermogravimetric analysis (TGA) was employed to select the weight changes of functionalized mesoporous MCM-41. TGA curves for MCM-41(a) and MCM-41@fungus (b) are depicted in Figure 5. According to the TGA curve $b$, an initial weight loss was seen at temperatures below $200^{\circ} \mathrm{C}$ because of the removal of physically and chemically adsorbed water molecules inside the pores 
channels and surface hydroxyl groups. Additionally, at temperatures above $200^{\circ} \mathrm{C}$, large weight losses occurred which were mainly due to the decomposition of covalently bonded organics $\left(200-500^{\circ} \mathrm{C}\right)$ and silanol groups $\left(>500^{\circ}\right)$. This shows that the grafting of fungus had occurred on the inner pore channels of Si-MCM-41. MCM-41 has attracted great attention because of its large pore size and extremely high surface area especially above $1000 \mathrm{~m}^{2} / \mathrm{g}$ (Nikoorazm et al., 2015). The exceptionally high surface area and porous structure of MCM-41 make it as a potential efficient host material for a variety of supported catalysts (Nikoorazm et al., 2015). According to our results,

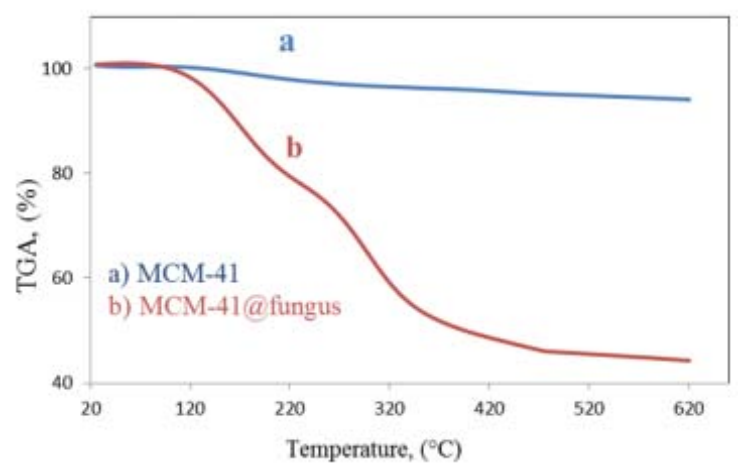

Figure 5. (a) TGA thermograms of MCM-41(a) and (b) MCM41@fungus of the entomopathogenic fungus Metarhizium anisopliae: At temperatures above $200^{\circ} \mathrm{C}$, large weight losses occurred which were mainly due to the decomposition of covalently bonded organics $\left(200-500^{\circ} \mathrm{C}\right)$ and silanol groups $\left(>500^{\circ}\right)$, indicating grafting of fungus on the inner pore channels of Si-MCM-41. the entomopathogenic fungus $M$. anisopliae was grafted to MCM-41 through the hydrox$\mathrm{yl}$ group of the fungus leading to the synthesis of MCM-41@fungus.

\section{MCM-41@fungus against eggs and neo- nate larvae of $P$. operculella}

The results of the bioassays for PEF and MCM-41@fungus against eggs and neonate larval penetration of PTM are presented in Table 1. LC 50 values of PEF and MCM-41@fungus were $1.7 \times 10^{7}$ and $2.0 \times 10^{5}$ conidia/ $/ \mathrm{ml}$ on eggs and $1.8 \times 10^{6}$ and $1.5 \times 10^{4}$ conidia $/ \mathrm{ml}$ on neonate larvae, respectively. Hence, at both life stages, $\mathrm{LC}_{50}$ values of nano-formulated entomopathogenic fungus against $P$. operculella were significantly lower thus more effective than pure M. anisopliae, as indicated by the absence of overlapping of confidence limits. Sabbour (2014) also found similar results on the efficacy of nano-formulated destruxin of $M$. anisopliae against adult females of Hetiracris littoralis Rambur (Orthoptera: Acrididae) under laboratory conditions, i.e., in nano-formulated samples, $\mathrm{LC}_{50}$ values were significantly decreased.

Susceptibility of potato tuber moth larvae to Baeuveria bassiana and M. anisopli$a e$ and the role of chemical additives in enhancing the action of entomopathogenic fungi were assessed by Sabbour (2002) who noted that oxalic and citric acids demonstrated the highest improvement of $M$. anisopliae efficacy against first instar lar-

Table 1. Toxicity of Metarhizium anisopliae and MCM-41@fungus to eggs and first instar larvae of Phthorimaea operculella under laboratory conditions.

\begin{tabular}{l|c|c|c|c|c}
\hline $\begin{array}{l}\text { Growth } \\
\text { stages }\end{array}$ & Treatments & Slope \pm S. E. & $X^{2}(\mathrm{df})$ & $\mathrm{LC}_{50}$ (conidia/ml) & $\mathrm{LC}_{90}$ (conidia/ml) \\
\hline Egg & PEF & $3.74 \pm 0.05$ & $1.47(3)$ & $\begin{array}{c}1.7 \times 10^{7} \\
\left(6.3 \times 10^{6}-5.2 \times 10^{7}\right) \\
2.0 \times 10^{5}\end{array}$ & $\begin{array}{c}9.2 \times 10^{10} \\
\left(8.9 \times 10^{9}-6.9 \times 10^{12}\right) \\
1.5 \times 10^{9}\end{array}$ \\
\hline & MCM-41@fungus & $4.26 \pm 0.08$ & $1.26(3)$ & $\begin{array}{c}\left(7.1 \times 10^{4}-6.6 \times 10^{5}\right) \\
\left(1.2 \times 10^{8}-1.9 \times 10^{11}\right)\end{array}$ \\
\hline $\begin{array}{l}\text { Neonate } \\
\text { larvae }\end{array}$ & PEF & $3.94 \pm 0.06$ & $1.00(3)$ & $\begin{array}{c}1.8 \times 10^{6} \\
\left(6.6 \times 10^{5}-6.1 \times 10^{6}\right) \\
1.5 \times 10^{4}\end{array}$ & $\begin{array}{c}1.4 \times 10^{10} \\
\left(1.2 \times 10^{9}-1.7 \times 10^{12}\right) \\
1.4 \times 10^{8}\end{array}$ \\
\hline
\end{tabular}

PEF: Pure Entomopathogenic Fungus (=non-formulated fungus) $95 \%$ fiducial limit $(\mathrm{FL})$ is shown in parenthesis 
vae of $P$. operculella $\left(L_{50}\right.$ values $=1.20 \times 10^{7}$ and $1.30 \times 10^{7}$ conidia/ml, respectively, compared with $\mathrm{LC}_{50}=8.61 \times 10^{7}$ conidia $/ \mathrm{ml}$ for $M$. anisopliae alone). All $\mathrm{LC}_{50}$ values were higher than the $\mathrm{LC}_{50}$ value of PEF obtained from our results on larvae, possibly due to variations in the isolates and experimental procedures, however the chemical additives increased the efficiency of $M$. anisopliae against the pest. On the other hand, Khorrami et al. (2018) found a lower $\mathrm{LC}_{50}$ value (= $1.9 \times 10^{5}$ conidia/ml) relatively to our results for pure M. anisopliae, which could be also attributed to variation in the entomopathogenic fungus isolate. Other studies have also revealed the efficacy of $M$. anisopliae in pest control (Lacey et al., 1994; Ansari et al., 2004, 2007; Marannino et al., 2006; Meyling and Eilenberg, 2007; Baker et al., 2018) while Khorrami et al. (2018) evaluated the pathogenicity of $M$. anisopliae against the potato tuber moth in comparison with Nomuraea rileyi and Paecilomyces tenuipes. In the latter study, N. rileyi presented the highest toxicity against neonate larvae of PTM in laboratory conditions ( $\mathrm{LC}_{50}$ value equivalent to $1.0 \times 10^{3}$ conidia $/ \mathrm{ml}$ ) whereas $M$. anisopliae and $P$. tenuipes had lower activity $\left(\mathrm{LC}_{50}\right.$ values equivalent to $1.9 \times 10^{5}$ and $2.4 \times 10^{6}$ conid$\mathrm{ia} / \mathrm{ml}$, respectively).

Based on our findings on the effect of pure M. anisopliae and MCM-41@fungus, neonate larvae are more susceptible to infection by $M$. anisopliae than its eggs, which is consistent with the conclusions of Khorrami et al. (2018). Similarly, Sewify et al. (2000) reported that $M$. anisopliae has a potential for control of potato tuber moth larvae. They also reported that the combination of $M$. anisopliae and phoGV had a synergistic effect for larval control. Pandey et al. (2015) examined efficacy of $M$. anisopliae against PTM under laboratory conditions and exhibited that the fungus showed high biological activity against $P$. operculella larvae with $\mathrm{LC}_{50}$ values, ranging from $2.94 \times 10^{5}$ to $7.16 \times 10^{7}$ conidia/ml. In addition, Marannino et al. (2006) found that M. anisopliae isolates were more virulent to neonate larvae of Capnodis tenebrionis Eschscholtz than the eggs of the pest. The results are promising since the first larval stage is the only freeliving stage exhibiting a potential practical target in storage. To our knowledge, MCM41 has not been used as carrying agent in bio-pesticides and this is the first report of using of MCM-41 as carrying agent that can significantly improve the effectiveness of the $M$. anisopliae on eggs and neonate larvae of $P$. operculella. The experimental protocol followed in the present study allowed us to provide evidence for MCM-41@entomopathogenic fungus infection.

\section{Conclusion}

Laboratory bioassays have clearly demonstrated the pathogenicity of $M$. anisopliae and MCM-41@M. anisopliae for neonate larvae and eggs of $P$. operculella. These biocontrol agents should be considered for the development of a new and environmentally compatible approach for potato tuber moth management in terms of preventing PTM infestations. Further research is required to determine the biological activities of MCM-41$@ M$. anisopliae and its persistence after store applications and other factors that may improve its performance against $P$. operculella throughout its egg and larval stages.

\section{Literature Cited}

Abdollahi-Alibeik, M. and Pouriayevali, M. 2011. 12Tungstophosphoric acid supported on nano sized MCM-41 as an efficient and reusable solid acid catalyst for the three-component imino Diels-Alder reaction. Reaction, Kinetics, Mechanism and Catalysis, 104: 235.

Ansari, M.A., Shah, F.A., Whittaker, M., Prasad, M. and Butt, T. M. 2007. Control of western flower thrips (Frankliniella occidentalis) pupae with Metarhizium anisopliae in peat and peat alternative growing media. Biological Control, 40: 293-297.

Ansari, M.A., Vestergaard, S., Tirry, L. and Moens, M. 2004. Selection of a highly virulent fungal isolate, Metarhizium anisopliae CLO 53, for controlling Hoplia philanthus. Journal of Invertebrate $\mathrm{Pa}$ thology, 85: 89-96.

Baker, D.K., Rice, S.J., Leemon, D.M. and James, P.J. 2018. Horizontal transmission of Metarhizium 
anisopliae (Hypocreales: Clavicipitacea) and the effects of infection on oviposition rate in laboratory populations of Musca domestica (Diptera: Muscidae). Pest Management Science, 74: 987991.

Cai, Q., Luo, Z.S., Pang, W.Q., Fan, Y.W., Chen, X.H. and Cui, F. Z. 2001. Dilute solution routes to various controllable morphologies of MCM-41 silica with a basic medium. Chemistry of Materials, 13: 258-263.

Chen, C.Y., Li, H.X., and Davis, M.E. 1993. Studies on mesoporous materials: I. Synthesis and characterization of MCM-41. Microporous Materials, 2(1): 17-26.

Collantes, L.G., Raman, K.V. and Cisneros, F.H. 1986. Effect of six synthetic pyrethroids on two populations of potato tuber moth, Phthorimaea operculella (Zeller) (Lepidoptera: Gelechiidae), in Peru. Crop Protection, 5: 355-357.

Germchi, S., Khorshidi-Benam, M.B., HassanPanah, D. and Shekari, F. 2011. Effect of thiourea on dormancy breaking and minituber yield of potato (Solanum tuberosum L.) cv. Agria in greenhouse experiment. Journal of Food, Agriculture and Environment, 9: 379-382.

Goettel, M.S., Eilenberg, J. and Glare, T. 2005. Entomopathogenic fungi and their role in regulation of insect populations. In Comprehensive molecular insect science. Elsevier, Amsterdam, The Netherlands, p. 361-405.

Golizadeh, A. and Zalucki, M.P. 2012. Estimating temperature-dependent developmental rates of potato tuber worm, Phthorimaea operculelIa (Lepidoptera: Gelechiidae). Insect Science, 19: 609-620.

Inglis, G.D., Enkerli, J. and Goettel, M.S. 2012. Laboratory techniques used for entomopathogenic fungi: Hypocreales. In Manual of Techniques in Invertebrate Pathology (Second Edition). Academic Press: London, p. 189-253.

Khorrami, F., Mehrkhou, F., Mahmoudian, M. and Ghosta, Y. 2018. Pathogenicity of three different entomopathogenic fungi, Metarhizium anisopliae IRAN 2252, Nomuraea rileyi IRAN 1020C and Paecilomyces tenuipes IRAN 1026C against the potato tuber Moth, Phthorimaea operculella Zeller (Lepidoptera: Gelechiidae). Potato Research, 61(4): 297-308.

Kroschel, J. and Sporleder, M. 2006. Ecological approaches to integrated pest management of the potato tuber moth, Phthorimaea operculella Zeller (Lepidoptera, Gelechidae). In Proceedings of the $45^{\text {th }}$ annual Washington State potato conference. Moses Lake, Washington, p. 85-94.

Lacey, L.A. 2012. editor. Manual of techniques in invertebrate pathology. Academic Press.

Lacey, L.A., Horton, D.R., Chauvin, R.L. and Stocker, J.M. 1999. Comparative efficacy of Beauveria bassiana, Bacillus thuringiensis, and aldicarb for control of Colorado potato beetle in an irrigated desert agroecosystem and their effects on biodiversity. Entomologia Experimentalis et Applicata, 93: 189-200.

Lacey, L.A., Martins, A.N. and Ribeiro, C.A. 1994. The pathogenicity of Metarhizium anisopliae and Beauveria bassiana for adults of the Japanese beetle, Popillia japonica (Coleoptera: Scarabaeidae). European Journal of Entomology, 91: 313319.

Llanderal-Cázares, C., Lagunes-Tejeda, A., CarrilloSánchez, J.L., Sosa-Moss, C., Vera-Graziano, J. and Bravo-Mojica, H. 1996. Susceptibility of Phthorimaea operculella (Zeller) to insecticides. Journal of Entomological Science, 31: 420-426.

Marannino, P., Santiago-Álvarez, C., de Lillo, E. and Quesada-Moraga, E. 2006. A new bioassay method reveals pathogenicity of Metarhizium anisopliae and Beauveria bassiana against early stages of Capnodis tenebrionis (Coleoptera; Buprestidae). Journal of Invertebrate Pathology, 93: 210-213.

Meyling, N.V. and Eilenberg, J. 2007. Ecology of the entomopathogenic fungi Beauveria bassiana and Metarhizium anisopliae in temperate agroecosystems: potential for conservation biological control. Biological Control, 43: 145-155.

Nikoorazm, M., Ghorbani-Choghamarani, A., Ghorbani. F., Mahdavi, H. and Karamshahi, Z. 2015. Bidentate salen Cu (II) complex functionalized on mesoporous MCM-41 as novel nano catalyst for the oxidative coupling of thiols into disulfides using urea hydrogen peroxide (UHP). Journal of Porous Materials, 22: 261-267.

Pandey, S., Sporleder, M., Chherty, Y.D.G., Giri, Y.P. and Kroschel, G. 2015. Efficacy of Metarhizium anisopliue (NLetsch.) Sorokin against the potato tuber moth, Phthorimaea operculella (Zeller) in consumable potato, under laboratory conditions. Nepalese Horticulture, 10: 47-54.

Radcliffe, E. B. 1982. Insect pests of potato. Annual Review of Entomology, 27: 173-204.

Rath, D. and Parida, K. M. 2011. Copper and nickel modified MCM-41 an efficient catalyst for hydrodehalogenation of chlorobenzene at room temperature. Industrial and Engineering Chemistry Research, 50: 2839-2849.

Sabbour, M.M. 2002. The role of chemical additives in enhancing the efficacy of Beauveria bassiana and Metarhizium anisopliae against the potato tuber moth Phthorimaea operculella (Zeller) (Lepidoptera: Gelechiidae). Pakistan Journal of Biological Science, 5(11): 1155-1159.

Sabbour, M.M. 2014. Evaluating toxicity of extracted nano-Destruxin against the desert locust Schistocerca gregaria in Egypt. The Journal of Egyptian Academic Society of Environmental Development, 15: 9-17.

Santi, L., da Silva, W.O., Berger, M., Guimarães, J.A., 
Schrank, A. and Vainstein, M.H. 2010. Conidial surface proteins of Metarhizium anisopliae: Source of activities related with toxic effects, host penetration and pathogenesis. Toxicon, 55 : 874-880.

Sewify, G.H., Abol-Ela, S., and Eldin, M.S. 2000. Effects of the entomopathogenic fungus Metarhizium anisopliae (Metsch.) and granulosis virus (GV) combinations on the potato tuber moth Phthorimaea operculella (Zeller) (Lepidoptera: Gelechiidae). Bulletin of Faculty of Agriculture, University of Cairo, 51(1): 95-106.

Sharma, A. and Gupta, R. 2009. Biological activity of some plant extracts against Pieris brassicae (Linn.). Journal of Biopesticide, 2: 26-31.
Shylesh, S. and Singh, A.P. 2005. Vanadium-containing ordered mesoporous silicates: Does the silica source really affect the catalytic activity, structural stability, and nature of vanadium sites in V-MCM-41?. Journal of Catalysis, 2: 359-371.

Wraight, S.P. and Ramos, M.E. 2005. Synergistic interaction between Beauveria bassiana-and Bacillus thuringiensis tenebrionis-based biopesticides applied against field populations of Colorado potato beetle larvae. Journal of Invertebrate $\mathrm{Pa}$ thology, 90: 139-150.

Received: 26 January 2019; Accepted: 14 November 2021

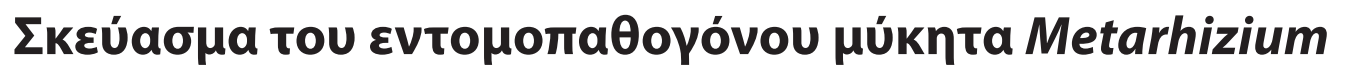

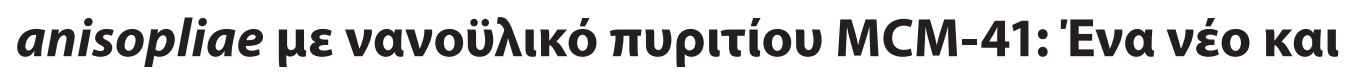

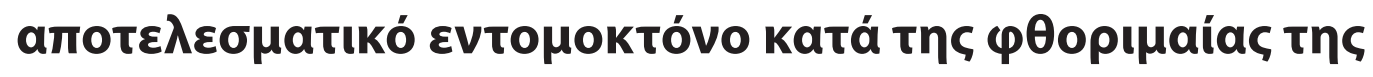

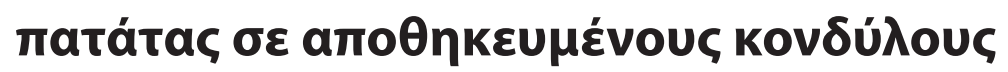

\author{
F. Khorrami, A. Soleymanzade, H. Batmani kaı Y. Ghosta
}

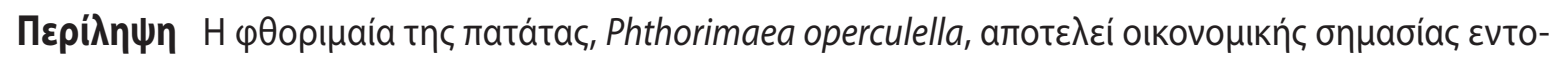

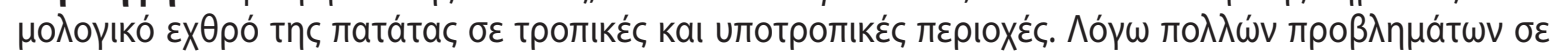

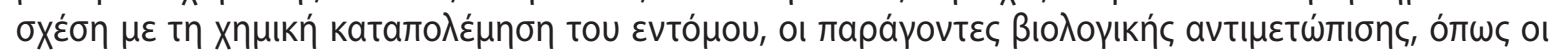

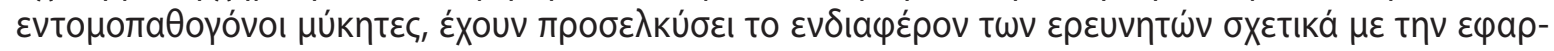

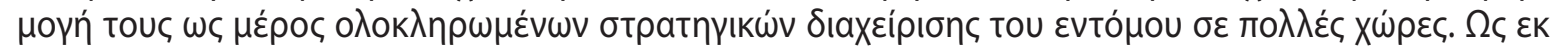

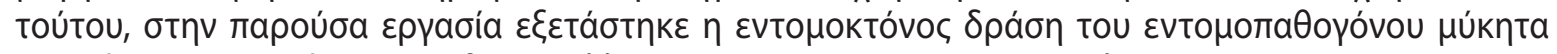

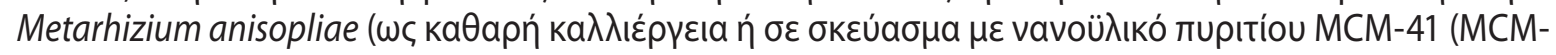

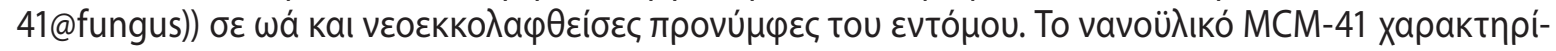

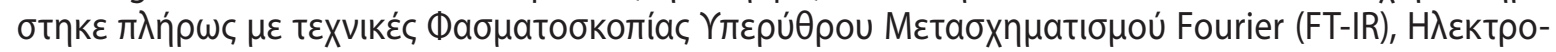

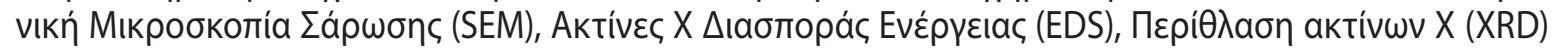

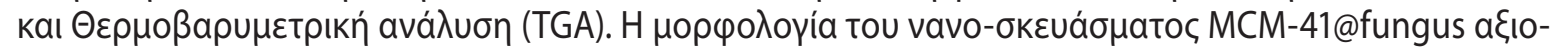
$\lambda$ орйө

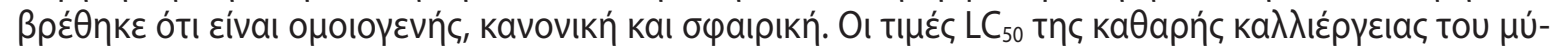

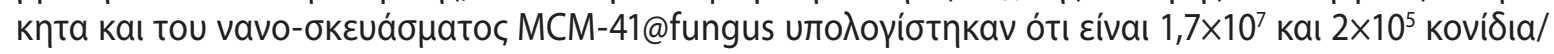

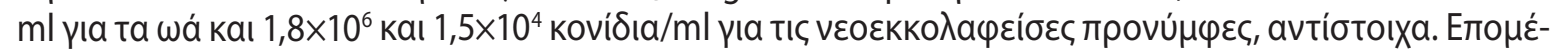

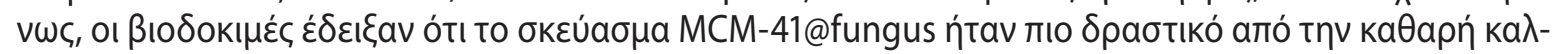

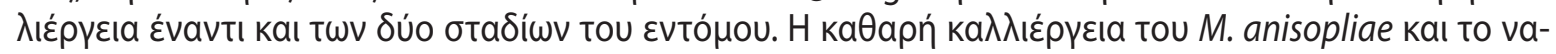

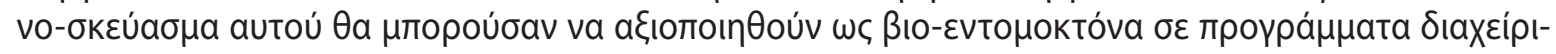

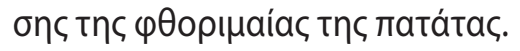

Hellenic Plant Protection Journal 15: 21-29, 2022 